\title{
A treasure trove of Cambrian fossils
}

\author{
Allison C. Daley \\ Institute of Earth Sciences, University of Lausanne, Geopolis, CH-1015 Lausanne, Switzerland. E-mail: allison.daley@unil.ch
}

One of the most important discoveries in paleontological history was the Burgess Shale in the Canadian Rocky Mountains in 1909 by Charles Walcott. This 508 million-year-old fossil locality is extraordinary because the exquisite fossils preserved there are soft-bodied, showing skin, eyes, and internal organs such as guts and brains. The Burgess Shale and many similar localities found since then-including the equally diverse and important Chengjiang Biota of China (1), numerous other sites in China (2), and the Emu Bay Shale in Australia (3)-record the sudden appearance of a huge diversity of animals in a geologically short period of time, an event called the Cambrian Explosion (4). On page xxx of this issue, Fu et al. (5) reveal a stunning new locality, the Qingjiang biota, which is slightly older in age (518 million years) than the Burgess Shale and yields fossils that fill gaps in our knowledge and raise interesting questions about the earliest animal ecosystems.

Fossil localities such as the Burgess Shale reveal the soft tissues and entirely soft-bodied organisms that typically do not make it into the fossil record, and provide a detailed window into what animal life looked like during the earliest stages of its evolution (4). Many of these animals have anatomies that do not directly resemble anything alive today, leading to lively debates on how they may be related to living animals. Other than the Burgess Shale (508 million years old) and the Chengjiang biota (518 million years old), numerous localities around the world were reported in the 20th century, including from Canada, China, USA, Poland, Spain, and Australia (6). Burgess Shale-type fossils have even been found in the early Ordovician Fezouata Biota ( 480 million years ago), showing that some Cambrian taxa were long-lived (7).

The past ten years have seen a big jump in the discovery of new Burgess Shale-type fossil localities, based on detailed mapping and highly focused collection efforts, including several near the original Burgess Shale locality (8). The Qingjiang biota from China reported by Fu et al. stands out even among these for the extreme abundance of the fossil material and the exceptionally high fidelity of anatomical preservation. The fossils are pristine and untouched by metamorphism or weathering, making them exceptionally good candidates for studying the fossilization processes that preserved the tissues in such extraordinary detail.

Owing to the exceptional preservation of soft tissues, Burgess Shale-type fossils include representatives of nearly all major animal phyla. Among these fossils, the most abundant and diverse are the sponges and arthropods (including insects, crustaceans, millipedes, and arachnids) $(1,9)$. The earliest members of our own phylum, the chordates, are found as small fishlike creatures.

The cnidarians, which include corals, sea anemones, and jellyfish, are relatively rare and not particularly diverse in previously known Cambrian Explosion localities (10). In contrast, the Qingjiang biota reveals a high abundance and diversity of cnidarians, which make up over a third of the specimens reported by Fu et al. Free-swimming jellyfish and sea anemones attached to the sea floor are both present, with detailed anatomies that make them instantly recognizable. There are also stunning new specimens of comb jellies (ctenophores), which are basal animals with an unclear phylogenetic position relative to the rest of the animal phyla. It has been suggested that ctenophores could be the most basal animal, or that they are more closely related to the cnidarians in a scenario where sponges are the most basal animal (11). The Qingjiang biota will thus be highly informative for resolving the relationships between the earliest-diverging animal phyla. The anatomical data from the site could, for example, help to resolve whether ctenophores or sponges are the most basal animal - a debate that remains unsolved even with molecular data. (11).

The presence in the Qingjiang biota of diverse kinorhynchs (mud dragons) is also highly unexpected. These moulting invertebrates are less than $1 \mathrm{~mm}$ in length and live buried in modern-day marine sediments. Kinorhynchs have only been found once so far in the fossil record, as tiny three-dimensional phosphatic microfossils from the early Cambrian (12). The Qingjiang biota reveals at least three new kinorynch-like taxa with lengths of up to $4 \mathrm{~cm}$, which seem to have lived on the seafloor rather than buried within it. Could the evolution of this phylum be characterized by large early-diverging taxa that progressively reduced their body size as they buried deeper into the seafloor? A closely related phylum, Loricifera, is also represented by macroscopic Cambrian taxa and microscopic modern taxa (13), suggesting a possible parallel trend in evolution that warrants further investigation. Fossils from the Qingjiang biota will be instrumental in unravelling the evolutionary history of these enigmatic and poorly known animal phyla.

One of the most remarkable findings reported by Fu et al. is that $53 \%$ of the animals and algae in the Qingjiang biota represent previously unknown taxa. As these taxa are described in detail, the Qingjiang Biota will help to illuminate the reasons for faunal variation between localities. The Burgess Shale and the Chengjiang Biota, for example, have some similarities in the overall type and abundance of animals found at each site, but only $15 \%$ of genera are found at both localities (9). Differences in the faunal assemblage between the Burgess Shale and Chengjiang Biota could be attributed to many things, such as differences in age, paleogeographic position, and environmental conditions. The Qingjiang biota can help to determine which of these factors drove the faunal differences. Only about 8\% of species are found in both the Qingjiang and the Chengjiang biota (5), even though the sites are the same age and were located in a similar paleogeographic position. This means that their disparate faunal compositions must be the result of paleoenvironmental differences, with the Qingjiang occupying a slight deeper marine habitat.

Fu et al. convincingly demonstrate that the Qingjiang biota represents an assemblage of organisms that was preserved nearly in place, providing a snapshot of a real animal community 518 million years ago. The treasure trove of the Qingjiang biota provides an exciting opportunity to explore how paleoenvironmental conditions influenced ecological structuring and evolutionary drivers during the Cambrian Explosion.

REFERENCES:

1.X.G. Hou et al., The Cambrian Fossils of Chengjiang: The Flowering of Early Animal Life, Wiley Blackwell (2017).

2. X. Zhang, Gondwana Res. 14, 255 (2008). 
3. J.R. Paterson et al. J. Geol. Soc. London 173, 1 (2016).

4. A.C. Daley et al., Proc. Natl. Acad. Sci. U.S.A. 115, 5323 (2018).

5. D. Fu et al., Science XXX, YYY (2019)

6. R.R. Gaines, Paleontol. Soc. Papers 20, 123 (2014).

7.P. Van Roy et al., J. Geol. Soc. London 172, 542 (2015).

8. J-B. Caron et al., Nat. Commun. 5, 3210 (2014).

9. L. Babcock et al., GSA Today 11, 2 (2001).

10. Q. Ou et al., Proc. Natl. Acad. Sci. U.S.A. 114, 8835 (2017)

11. P. Simion et al., Curr. Biol. 27, 958-67 (2017).

12. H. Zhang et al., Sci. Reports 5, 16521 (2015).

13. J. Peel, J. Paleontol. 84, 332 (2010). 